\title{
Isopropyl Caffeate: A Caffeic Acid Derivative-Antioxidant Potential and Toxicity
}

\author{
Andressa Brito Lira $\mathbb{D}^{1}{ }^{1}$ Camila de Albuquerque Montenegro, ${ }^{2}$ \\ Kardilandia Mendes de Oliveira, ${ }^{3}$ Abrahão Alves de Oliveira Filho, ${ }^{4}$ \\ Alexandre Rolim da Paz, ${ }^{5}$ Marianna Oliveira de Araújo, ${ }^{1}$ Damião Pergentino de Sousa $\mathbb{D}^{1}, 3,6$ \\ Cynthia Layse Ferreira de Almeida ${ }^{\mathbb{D}},{ }^{7}$ Teresinha Gonçalves da Silva ${ }^{\mathbb{D}},{ }^{7,8}$ \\ Caliandra Maria Bezerra Luna Lima, ${ }^{9}$ Margareth de Fátima Formiga Melo Diniz, ${ }^{1,3,6}$ \\ and Hilzeth de Luna Freire Pessôa ${ }^{3,10}$
}

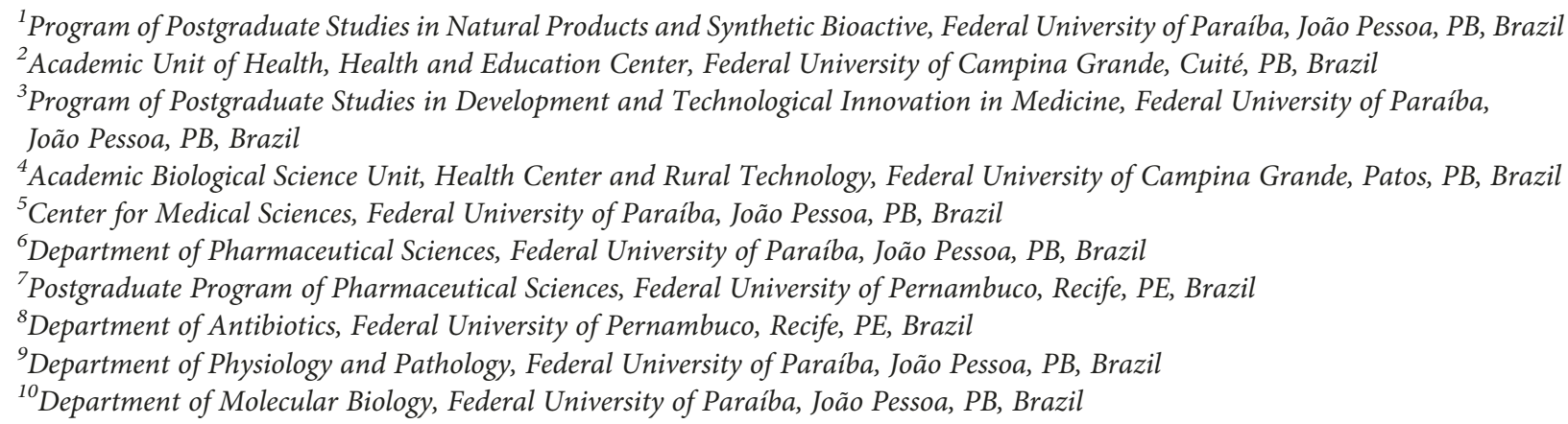

Correspondence should be addressed to Andressa Brito Lira; andressabritolira@hotmail.com

Received 24 November 2017; Revised 19 February 2018; Accepted 8 March 2018; Published 19 April 2018

Academic Editor: Eric E. Kelley

Copyright (c) 2018 Andressa Brito Lira et al. This is an open access article distributed under the Creative Commons Attribution License, which permits unrestricted use, distribution, and reproduction in any medium, provided the original work is properly cited.

\begin{abstract}
Phenolic compounds, among them isopropyl caffeate, possess antioxidant potential, but not without toxicity and/or adverse effects. The present study aimed to evaluate the antioxidant activity and toxicity of isopropyl caffeate through in silico, in vitro and in vivo testing. The results showed that isopropyl caffeate presents no significant theoretical risk of toxicity, with likely moderate bioactivity: GPCR binding, ion channel modulation, nuclear receptor binding, and enzyme inhibition. Isopropyl caffeate induced hemolysis only at the concentrations of 500 and $1000 \mu \mathrm{g} / \mathrm{ml}$. We observed types A and O erythrocyte protection from osmotic stress, no oxidation of erythrocytes, and even sequestrator and antioxidant behavior. However, moderate toxicity, according to the classification of GHS, was demonstrated through depressant effects on the central nervous system, though there was no influence on water and food consumption or on weight gain, and it did present possible hepatoprotection. We conclude that the effects induced by isopropyl caffeate are due to its antioxidant activity, capable of preventing production of free radicals and oxidative stress, a promising molecule with pharmacological potential.
\end{abstract}

\section{Introduction}

Phenolic compounds are widely distributed in plants; they protect against UV light, insects, bacteria, and viruses, all while inhibiting the growth of competitor plants $[1,2]$. They are traditionally considered potent natural antioxidants because of their ability to eliminate hydroxyl radicals, aiding in the prevention of diseases associated with oxidative stress in membranes, proteins, and DNA [2-4]. 
Isopropyl caffeate is a derived esterification of caffeic acid (Figure 1). This acid has low solubility, yet adding a chain alkyl to the molecule changes its lipophilicity, increasing permeability through the cell membrane and influencing its bioavailability $[5,6]$.

Isopropyl caffeate has also demonstrated various biological activities such as antinociceptive activity similar to that of licensed drugs [7], antioxidant activity according to the DPPH model [6], antitumor activity against different tumor strains [5, 6], activity significantly improving the in vitro inhibitory properties of renin [8], and antifungal effect against cellular and planktonic biofilm [9].

It is worth noting that no chemical is free of toxicity; the study of toxic effects is as necessary as knowledge concerning side effects, interactions, contraindications, and mutagenicity [10-12]. Substance toxicity is often related to the formation of free radicals, which cause oxidative stress and are responsible for a large number of diseases [13-15].

Oxidative stress is characterized as an imbalance between the production of reactive species and antioxidant defense activity [13-15]. It is noteworthy that free oxygen radicals involved in the etiology of inflammation cause damage to macromolecules, lipid peroxidation [16-18], and lead to cell apoptosis $[17,18]$.

In this context, our study examined isopropyl caffeate; initially using an in silico approach to characterize possible theoretical pharmacological and toxicological activities, we then investigated cytotoxicity and antioxidant effects, and finally, in vivo acute toxicity was determined.

\section{Materials and Methods}

2.1. General Procedure for the Synthesis of Isopropyl Caffeate. A mixture of caffeic acid $(0.25 \mathrm{~g})$ and isopropyl alcohol $(50 \mathrm{ml})$ was heated under reflux in the presence of sulfuric acid $(0.4 \mathrm{ml})$ until the completion of its reaction ( 8 hours), which was checked by a single spot in TLC. Then, alcohol was removed under reduced pressure and the solution was diluted with $20 \mathrm{ml}$ of water. The product was extracted with ethyl acetate $(15 \mathrm{ml})$. The organic phase was neutralized successively with $5 \%$ sodium bicarbonate and water, dried over anhydrous sodium sulfate, and filtered. After evaporation under reduced pressure, the phase yielded the ester derivative [19].

2.2. Isopropyl Caffeate. Black amorphous solid; yield $93.06 \%$; Mp 155-160 ${ }^{\circ} \mathrm{C}$; IR umax $\left(\mathrm{KBr}, \mathrm{cm}^{-1}\right)$ : 3307, 3047, 2976, 1677, 1594 e 1442, 1277 e 1188. ${ }^{1} \mathrm{H}$ NMR (DMSO-d6, $200 \mathrm{MHz}): \delta \mathrm{H} 1.23(6 \mathrm{H} ; \mathrm{d} ; J=6.2 \mathrm{~Hz}), 4.98$ (1H; sept; $J=6.2 \mathrm{~Hz}), 6.23(1 \mathrm{H}$; d; $J=15.8 \mathrm{~Hz}), 6.75(1 \mathrm{H}$; d; $J=8.0 \mathrm{~Hz})$, $6.99(1 \mathrm{H} ; \mathrm{dd} ; J=8.0,2.0 \mathrm{~Hz}), 7.04(1 \mathrm{H} ; \mathrm{d} ; J=2.0 \mathrm{~Hz}), 7.44$ $(1 \mathrm{H} ; \mathrm{d} ; J=16.0 \mathrm{~Hz}),{ }^{13} \mathrm{C}$ NMR $(\mathrm{CD} 3 \mathrm{OD}, 50 \mathrm{MHz}): \delta \mathrm{C} 22.2$, $69.0,115.1,115.6,116.5,122.9,127.6,146.6,146.7,149.4$, and 168.8 [20]. The solubilization of the test product was performed with the aid of Cremophor RH 40 to 3\% for the experimental protocols in vitro. For the in vivo protocol, Cremophor RH 40 to $10 \%$ was used.

2.3. Human Erythrocytes. Human erythrocytes of blood types $\mathrm{A}, \mathrm{B}, \mathrm{O}$, and $\mathrm{AB}$ were obtained from bags containing

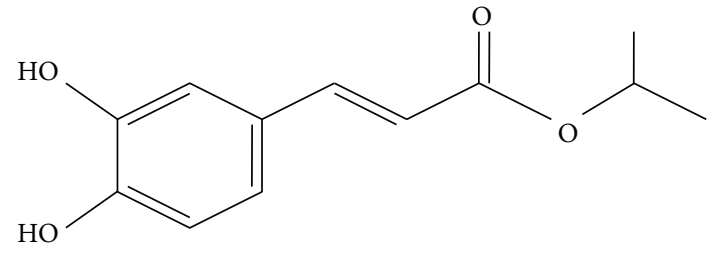

FIGURE 1: Isopropyl caffeate.

erythrocyte concentrate, from the Transfusion Unit of the Lauro Wanderley University Hospital of UFPB. The project was approved by the Research Ethics Committee at the Lauro Wanderley University Hospital of UFPB, with approval number 1.658.669.

2.4. Animals. To perform the in vivo assay, Mus musculus mice, females, of the Balb/c strain from the Fiocruz Permanbuco Vivarium and weighing between 22-29g were used. The mice were kept at a temperature of $21 \pm 1^{\circ} \mathrm{C}$, light and dark cycle of $12 \mathrm{~h}$, and fed with pellet-type feed and water ad libitum. This experimental protocol was approved by the Committee on Ethics in Animal Use of UFPB, with registration number 009/2016.

2.5. In Silico Study: Molinspiration. The isopropyl caffeate was checked for bioactivity by calculating the activity score for each: GPCR ligand, ion channel modulator, kinase inhibitor, and nuclear receptor ligand. All of the parameters were checked with the help of the online Molinspiration software drug-likeness score. The drug-likeness score for each compound was calculated, compared with its specific activity, and the results were compared with the drug standard [21].

2.6. In Silico Study: PASS Online. Prediction of the spectrum of activity for substances using (PASS) online was performed to assess the overall biological potential of the organic molecule for the human organism. Based on the structures of organic compounds, the program provides simultaneous predictions of many types of biological activity. Through molecular structural analysis, the program provides a set of likely activities, giving various facets of biological action for a compound by means of an interpretation of $\mathrm{Pa}$ (probability "to be active") and Pi (probability "to be inactive") rates [22].

2.7. In Silico Study: Estimation of Pharmacokinetic Parameters and Toxicology. The pharmacokinetic parameters and theoretical toxicological ADMET (absorption, distribution, metabolism, excretion, and toxicity) were calculated using the admetSAR tool. The parameters were hematoencephalic barrier permeability, permeability Caco-2, absorption in the intestine, substrates and inhibitors of cytochrome enzymes, and inhibitors of renal cation transport. Through this tool, metabolism using certain cytochrome P450 enzymes was evaluated comparing whether the compounds were substrates for cytochromes CYP450 2D6, CYP450 3A4, and CYP450 2C9; whether they were inhibitors of cytochrome CYP450 1A2, CYP450 2C9, CYP450 2D6, CYP450 2C19, and CYP450 3A4; and whether there was cytochrome inhibition promiscuity [23]. 
2.8. Hemolysis Assay in Human Erythrocytes. A suspension of $0.5 \%$ of human erythrocytes in $0.9 \% \mathrm{NaCl}$ was prepared. The solutions of isopropyl caffeate at different concentrations (10, $50,100,250,500$, and $1000 \mu \mathrm{g} / \mathrm{ml}$ ) were added to $2 \mathrm{ml}$ of the erythrocyte suspension. The cell suspension was used as a negative control ( $0 \%$ hemolysis), and the erythrocyte suspension plus Triton X-100 was used as a positive control (100\% hemolysis). The samples were incubated for $1 \mathrm{~h}$ under slow and constant stirring $(100 \mathrm{rpm})$ at $22 \pm 2^{\circ} \mathrm{C}$. Afterwards, they were centrifuged at $2500 \mathrm{rpm}$ for $5 \mathrm{~min}$. Hemolysis was measured by spectrophotometry at a wavelength of $540 \mathrm{~nm}$ [24]. All experiments were performed in triplicate and expressed as an average plus or minus the standard error of the mean.

2.9. Evaluation of Osmotic Fragility of Human Erythrocytes. Solutions of isopropyl caffeate at concentrations of 10, 50, $100,250,500$, and $1000 \mu \mathrm{g} / \mathrm{ml}$ were incubated in $2 \mathrm{ml}$ of a $0.5 \%$ suspension of erythrocytes for 1 hour at $25 \pm 2{ }^{\circ} \mathrm{C}$. After this, the preparations were centrifuged at $2500 \mathrm{rpm}$ for 5 minutes and the supernatant discarded. The erythrocytes were then resuspended in a hypotonic sodium chloride solution $(0.24 \%)$ solution and shaken at $100 \mathrm{rpm}$ for 20 minutes at $25 \pm 2{ }^{\circ} \mathrm{C}$. The hemolysis was quantified by spectrophotometry at $540 \mathrm{~nm} \mathrm{[25].} \mathrm{A} \mathrm{suspension} \mathrm{of} \mathrm{erythrocytes} \mathrm{was} \mathrm{used} \mathrm{as}$ a negative control ( $0 \%$ hemolysis), and a solution of erythrocytes in the presence of a $0.24 \%$ sodium chloride solution was used as a positive control (100\% hemolysis). The experiments were performed in triplicate, and the results expressed as \% hemolysis as compared to the positive control group.

\subsection{Assessment of Oxidant and Antioxidant Potential in} Human Erythrocytes in the Presence of Phenylhydrazine. To investigate the oxidizing potential, a 30\% hemoglobin solution in PBS supplemented with glucose $(200 \mathrm{mg} / \mathrm{dl})$, pH 7.6 was prepared. Isopropyl caffeate $(10,100,250,500$, and $1000 \mu \mathrm{g} / \mathrm{ml}$ ) was then added to $2 \mathrm{ml}$ of erythrocyte suspension and incubated for $1 \mathrm{~h}$ under slow and steady stirring $(100 \mathrm{rpm})$ at $25 \pm 2^{\circ} \mathrm{C}$. The samples were then centrifuged at $2500 \mathrm{rpm}$ for $5 \mathrm{~min}$, and the percentage of methemoglobin (MetHb) in relation to total hemoglobin $(\mathrm{Hb})$ was quantified by spectrophotometry at $630 \mathrm{~nm}$ and $540 \mathrm{~nm}$, respectively. The percentage of MetHb formed was compared to values obtained in the presence the phenylhydrazine $(\mathrm{PH})$, a proven oxidizing agent.

To investigate the antioxidant potential, after the incubation period of $1 \mathrm{~h}$, for the step described above, we added $1 \mathrm{mmol} / \mathrm{l}$ of phenylhydrazine. The solutions were aerated and kept under constant and slow agitation (100 rpm) for another $20 \mathrm{~min}$ to $25 \pm 2^{\circ} \mathrm{C}$. After this period, the samples were centrifuged at $2500 \mathrm{rpm}$ for $5 \mathrm{~min}$ and diluted in $\mathrm{PB}$, and the percentage of $\mathrm{MetHb}$ in relation to total $\mathrm{Hb}$ was quantified by spectrophotometry at $630 \mathrm{~nm}$ and $540 \mathrm{~nm}$, respectively.

The percentage of MetHb formed was compared with the values obtained for vitamin $\mathrm{C}(1000 \mu \mathrm{g} / \mathrm{ml})$, a proven antioxidant agent. The experiments were performed in triplicate, and the results expressed as the methemoglobin formation percentage, in function of hemoglobin-MetHb (\% $\mathrm{Hb})$ [26].
2.11. Evaluation of the Antioxidant Potential in Human Erythrocytes in the Presence of Reactive Oxygen Species. The experiment was carried out in accordance with a study by Khalili et al. [27], with modifications. Isopropyl caffeate (10, $100,250,500$, and $1000 \mathrm{mg} / \mathrm{ml}$ ) was incubated with $2 \mathrm{ml}$ of a $0.5 \%$ erythrocyte suspension in $0.9 \% \mathrm{NaCl}$. After $5 \mathrm{~min}$ of incubation, $0.5 \mathrm{ml}$ of $\mathrm{H}_{2} \mathrm{O}_{2}(0.3 \%)$ was added. An erythrocyte suspension was used as negative control ( $0 \%$ cell hemolysis), an erythrocyte suspension in the presence of $\mathrm{H}_{2} \mathrm{O}_{2}(0.3 \%)$ as positive control ( $100 \%$ hemolysis), and an erythrocyte suspension in the presence of $\mathrm{H}_{2} \mathrm{O}_{2}(0.3 \%)$ and vitamin $\mathrm{C}$ $(1000 \mu \mathrm{g} / \mathrm{ml})$ as the reference antioxidant. After $2 \mathrm{~h}$, the samples were centrifuged at $2500 \mathrm{rpm}$ for $10 \mathrm{~min}$, and hemolysis was quantified by spectrophotometry at $540 \mathrm{~nm} \mathrm{[24].}$

2.12. Acute Oral Toxicity Test Procedures. The in vivo toxicological properties were investigated according to OECD Guideline 423 with modifications [28]. The control group was orally administered dilution vehicle. The group treated with isopropyl caffeate initially received the starting dose of $300 \mathrm{mg} / \mathrm{kg}$, with subsequent repetition of the dose. Nonoccurrence of death directed the experiment to continue using the $2000 \mathrm{mg} / \mathrm{kg}$ dose, finalizing with another repetition. We used $3 \mathrm{Balb} / \mathrm{c}$ females per group, except in the control group (6 females). After administration of isopropyl caffeate, behavioral parameters were observed for signs of pharmacological effects on the central nervous system at 30, 60, 90, 120, 180 , and $240 \mathrm{~min}$ [29]. Food and water consumption was monitored daily, and body weight was recorded on day 0 (before dosing), day 7, and day 14. After 14 days, the animals were sacrificed by administration of excess anesthetic $(20 \mathrm{mg} /$ $\mathrm{kg}$ xylazine and $500 \mathrm{mg} / \mathrm{kg}$ ketamine). Blood was removed for laboratory analysis of biochemical parameters. Organs were weighed (the heart, stomach, spleen, liver, and kidneys), with subsequent histopathological examinations. Also, through quantification of malondialdehyde and nitric oxide, evaluation of the hepatic antioxidant system was performed.

2.12.1. Biochemical Parameters. Biochemical analyses were carried out using a ChemWell ${ }^{\circledR}$ automated biochemical analyzer (lab test) to determine the serum levels of glucose, urea, creatinine, cholesterol, aspartate aminotransferase (AST), alanine aminotransferase (ALT), and alkaline phosphatase.

2.12.2. Determination of Malondialdehyde (MDA) Concentration. Lipid peroxidation was measured through levels of MDA [30], with modifications. The tissues were homogenized in $\mathrm{KCl}$ solution $1.15 \%(\mathrm{~m} / \mathrm{v})(1 \mathrm{~g}$ of tissue $/ 5 \mathrm{ml})$ using a tissue grinder and then centrifuged at $1200 \mathrm{rpm}$ for 10 minutes, at $0^{\circ} \mathrm{C}$. After centrifugation, the supernatant was reacted with thiobarbituric acid (TBA $0.8 \%$ ) in the presence of acetic acid (20\%) and sodium dodecyl sulfate (SDS $8.1 \%$ ), for 60 minutes at $100^{\circ} \mathrm{C}$. After cooling, n-butanol was added to the reaction, the tubes were centrifuged, and the reading of the organic phase was performed in a microplate reader at a wavelength of $535 \mathrm{~nm}$. The standard curve was constructed using 1,3-tetraethoxypropane.

2.12.3. Measurement of Nitric Oxide (NO). The nitrite concentration in the liver homogenate obtained was used as an 
Table 1: Prediction of bioactivities calculated in software Molinspiration, for isopropyl caffeate.

\begin{tabular}{lcccccc}
\hline Substance & GPCR ligand & Ion channel modulator & Kinase inhibitor & Nuclear receptor ligand & Protease inhibitor & Enzyme inhibitor \\
\hline Isopropyl caffeate & -0.44 & 0.25 & -0.66 & -0.01 & -0.58 & -0.09 \\
\hline
\end{tabular}

TABLE 2: Suggestions indicating biological activities for isopropyl caffeate; analysis by PASS online tool.

\begin{tabular}{lcc}
\hline PA & PI & Activity \\
\hline 0.521 & 0.017 & Anticarcinogenic \\
0.603 & 0.084 & Antieczematic \\
0.545 & 0.024 & Antifungal \\
0.743 & 0.003 & Antihelmintic (nematodes) \\
0.611 & 0.013 & Antihypercholesterolemic \\
0.875 & 0.003 & Antihypoxic \\
0.547 & 0.044 & Anti-inflammatory \\
0.564 & 0.074 & Anti-ischemic, cerebral \\
0.751 & 0.005 & Antimutagenic \\
0.538 & 0.005 & Antioxidant \\
0.557 & 0.010 & Antiparasitic \\
0.651 & 0.011 & Antiprotozoal (Leishmania) \\
0.556 & 0.023 & Antipruritic \\
0.594 & 0.013 & Antipruritic, allergic \\
0.554 & 0.015 & Antipsoriatic \\
0.648 & 0.047 & Antiseborrheic \\
0.534 & 0.024 & Antisecretory \\
0.756 & 0.005 & Antiseptic \\
0.577 & 0.018 & Antithrombotic \\
0.584 & 0.012 & Antiulcerative \\
0.532 & 0.019 & Cytoprotectant \\
0.618 & 0.024 & Hepatoprotectant \\
0.659 & 0.005 & Antiviral drug (influenza) \\
0.639 & 0.010 & \\
0.767 & 0.004 &
\end{tabular}

index of nitric oxide production and was measured using the Griess reaction. Briefly, $50 \mu \mathrm{l}$ of each sample and $50 \mu \mathrm{l}$ of Griess reagent were placed in a 96-well microtiter plate, incubated at room temperature $\left(22^{\circ} \mathrm{C}\right)$ for $10 \mathrm{~min}$, while being protected from light. The absorbance was measured at a wavelength of $560 \mathrm{~nm}$ using a microplate reader, and the nitrite concentration was determined by comparing the sample absorbance to a standard curve for sodium nitrite. The experiments were performed in triplicate, and the results expressed in $\mu \mathrm{M}[31]$.

2.12.4. Anatomopathological and Histopathological Evaluation. After euthanasia, the organs were examined macroscopically; resection was made with consecutive weighing of the heart, stomach, liver, spleen, and kidneys (severed by sagittal incision). The organ indexes were calculated according to the formula: index = weight of component (mg)/animal's weight $(\mathrm{g})$. The tissue sections of the organs excised (the stomach, liver, spleen, and kidneys), fixed in formaldehyde solution 10\%, after 72 hours were resectioned for histopathological processing: dehydration with an increasing alcohol series (70 to 100\%), diaphanization in xylol, impregnating, and inclusion in paraffin, according to the usual methods. The reagent fragments were sectioned with a thickness of $3.0 \mu \mathrm{m}$, mounted on slides, and stained with hematoxylin and eosin and then examined under an optical microscope at 200 and 400x [32].

2.13. Statistical Analysis. Values are expressed as mean \pm standard deviation (SD). Statistical significance between groups was determined using a one-way analysis of variance (ANOVA) followed by Dunnett's test, with $p<0.05$ indicating significance. All statistical analyses were performed using GraphPad Prism 6.0 (GraphPad Software Inc., La Jolla, CA, USA).

\section{Results}

3.1. In Silico Tests: Molinspiration. Isopropyl caffeate was shown to be moderately active and likely produces its actions through physiological interaction as a GPCR ligand, an ion channel modulator, a nuclear receptor ligand, and enzyme inhibitor (Table 1). This result follows from a score of greater than 0.00 , which is likely to have significant biological activities. Values between -0.50 and 0.00 represent moderated bioactivity. If the score is less than -0.50 , the compound is presumed to be inactive $[33,34]$.

3.2. In Silico Tests: Pass Online. In this test, one may verify probabilities for isopropyl caffeate to be active (PA) with antieczematic, antihelmintic (nematodes), antihypercholesterolemic, antihypoxic, antimutagenic, antiprotozoal (Leishmania), antiseborrheic, antiseptic cytoprotective, free radical sequestrating, hepatoprotective, or lipid peroxidaseinhibiting properties (Table 2).

3.3. In Silico Tests: admetSAR. This test revealed that isopropyl caffeate has no theoretical toxicity, has good solubility, stability, and absorption, and does not suffer significant first pass metabolism in the liver or small intestine. However it is subject to active transportation, though the compound does not theoretically permeate the blood-brain barrier. Also, isopropyl caffeate was not classified as a substrate or as an inhibitor for the assessed CYP450 isoforms, possessing low promiscuity (Table 3 ).

3.4. In Vitro Hemolysis. The isopropyl caffeate was only able to promote hemolysis at concentrations of $500 \mu \mathrm{g} / \mathrm{ml}$ and $1000 \mu \mathrm{g} / \mathrm{ml}$, for the blood types A, B, and O. For the blood type $\mathrm{AB}$, only the concentration of $1000 \mu \mathrm{g} / \mathrm{ml}$ was able to promote hemolysis when compared to the negative control. The percentage of hemolysis observed at a concentration of $500 \mu \mathrm{g} / \mathrm{ml}$ ranged from $0.44 \%$ to $3.94 \%$, and at the 
TABLE 3: Sorting properties ADMET, calculated in software admetSAR, for isopropyl caffeate.

\begin{tabular}{|c|c|}
\hline Model & Isopropyl caffeate \\
\hline \multicolumn{2}{|l|}{ Absorption } \\
\hline Hematoencephalic barrier & BBB- \\
\hline Intestinal absorption man & $\mathrm{HIA}+$ \\
\hline Permeability to Caco-2 & Caco-2+ \\
\hline Substrate of glycoprotein-P & S \\
\hline Inhibitor of glycoprotein-P & NI \\
\hline Renal transport of organic cations & NI \\
\hline \multicolumn{2}{|l|}{ Distribution and metabolism } \\
\hline Substrate CYP450 2C9 & NS \\
\hline Substrate CYP450 2D6 & NS \\
\hline Substrate CYP450 3A4 & NS \\
\hline Inhibitor CYP450 1A2 & NI \\
\hline Inhibitor CYP450 2C9 & NI \\
\hline Inhibitor CYP450 2D6 & $\mathrm{NI}$ \\
\hline Inhibitor CYP450 2C19 & NI \\
\hline Inhibitor CYP450 3A4 & NI \\
\hline CYP inhibitor promiscuity & Low \\
\hline \multicolumn{2}{|l|}{ The excretion and toxicity } \\
\hline HERG & IF \\
\hline Toxicity in Ames test & NT \\
\hline Carcinogen & NC \\
\hline Biodegradation & Prone to degradation \\
\hline Acute oral toxicity & III \\
\hline \multicolumn{2}{|l|}{ ADMET profile prediction-regression } \\
\hline Aqueous solubility & $-2.7631(\operatorname{LogS})$ \\
\hline Permeability to Caco-2 & 0.2988 (LogPapp, cm/s) \\
\hline \multicolumn{2}{|l|}{ Toxicity } \\
\hline Acute oral toxicity (rats) & $1.8847(\mathrm{LD} 50, \mathrm{~mol} / \mathrm{kg})$ \\
\hline
\end{tabular}

+ (permeates); NI: does not inhibit; NS: not substrate; S: substrate; I: inhibits; IF: weak inhibitor; NT: not toxic; NC: not a carcinogen; HERG: gene related to light-a-go-go human.

concentration of $1000 \mu \mathrm{g} / \mathrm{ml}$, the range between the blood types was from $8.39 \%$ to $21.87 \%$, (Figures $2-5$ ).

3.5. In Vitro Osmotic Fragility. Isopropyl caffeate, at all concentrations tested, was capable of inhibiting hemolysis caused by osmotic differences selectively in blood types $\mathrm{A}$ and $\mathrm{O}$ and can be seen in Figures 6-9.

3.6. In Vitro Oxidant and Antioxidant in the Presence of Phenylhydrazine. Figure 10 shows that the isopropyl caffeate was unable to oxidize the cells at concentrations of 10,50 , and $100 \mu \mathrm{g} / \mathrm{ml}$, when compared to the negative control group $\mathrm{Hb}$, and no concentration was able to oxidize the cells when compared to the positive control group $(\mathrm{Hb}+\mathrm{Ph})$, characterizing no significant oxidant power in this substance. For antioxidant activity in the presence of phenylhydrazine, no reduction was observed in the percentage of methemoglobin formation in function of hemoglobin (MetHb/\% $\mathrm{Hb}$ ) as compared to the positive control group $(\mathrm{Hb}+\mathrm{Ph})$.
Blood A

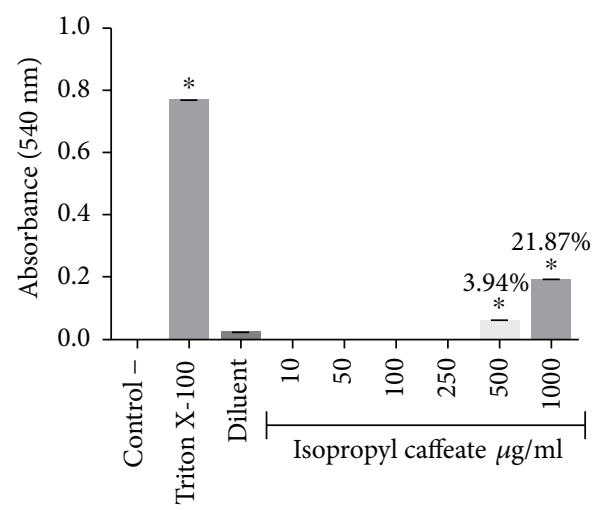

Figure 2: Hemolytic evaluation in type A erythrocytes, as induced by isopropyl caffeate. The results are expressed as mean \pm SD analysis by ANOVA followed by Dunnett's test, ${ }^{*} p<0.05(n=3)$.

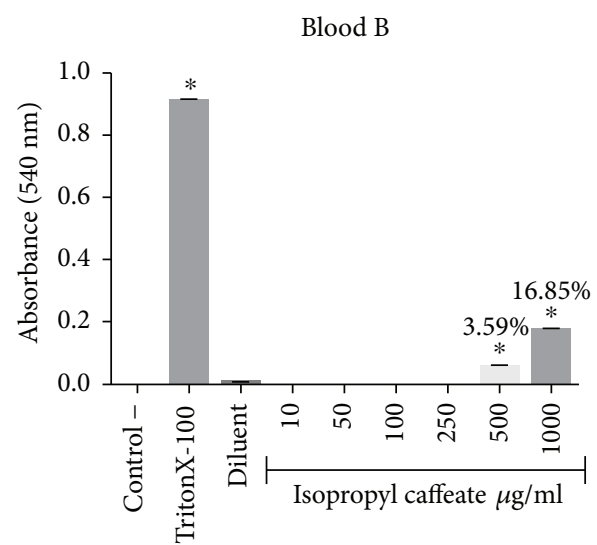

FIgURE 3: Hemolytic evaluation in type B erythrocytes, as induced by isopropyl caffeate. The results are expressed as mean \pm SD analysis by ANOVA followed by Dunnett's test, ${ }^{*} p<0.05(n=3)$.

3.7. In Vitro Antioxidant in the Presence of Reactive Oxygen Species. The ability of isopropyl caffeate at concentrations of $10,50,100$, and $250 \mu \mathrm{g} / \mathrm{ml}$ to sequestrate ROS was observed. A reduction of hemolysis induced by hydrogen peroxide $\left(\mathrm{H}_{2} \mathrm{O}_{2}\right)$ was verified when compared to the positive control group $\left(\mathrm{Hb}+\mathrm{H}_{2} \mathrm{O}_{2}\right)$. It is important to stress that isopropyl caffeate presented greater antioxidant power than vitamin $\mathrm{C}$ (Figure 11).

3.8. In Vivo Acute Toxicity: Behavioral Changes, Consumption of Water and Food and Weight Gain. In assessment of acute toxicity at the dose of $300 \mathrm{mg} / \mathrm{kg}$, there were no deaths. At this dose, depressive signs in central nervous system (CNS), such as reduction of hyperactivity, sedation, loss of atrial reflex, and response to touch, were identified. Also, signals related to the autonomic nervous system (ANS) were identified, such as constipation and decreased muscle tone. There were also decreases in self-cleaning and climbing behavior.

At a dose of $2000 \mathrm{mg} / \mathrm{kg}$, we observed similarities in the behavior of animals that had been treated with a dose of 
Blood O

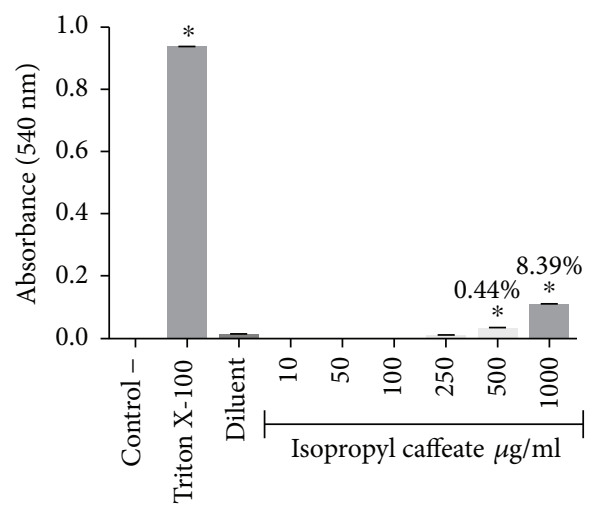

FIgURe 4: Hemolytic evaluation in type O erythrocytes, as induced by isopropyl caffeate. The results are expressed as mean $\pm \mathrm{SD}$ analysis by ANOVA followed by Dunnett's test, ${ }^{*} p<0.05(n=3)$.

Blood $\mathrm{AB}$

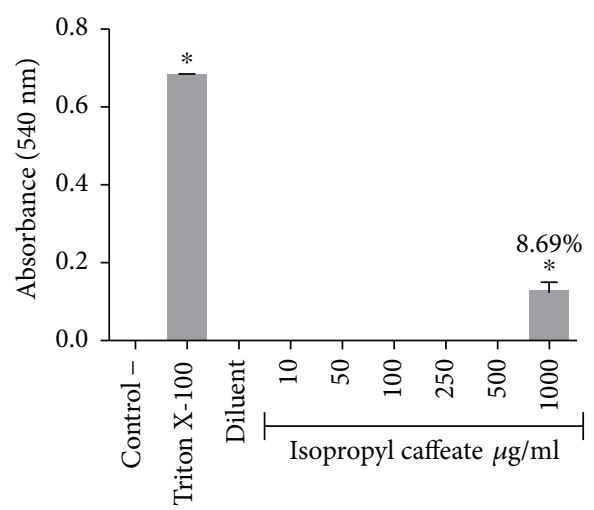

FIgURE 5: Hemolytic evaluation in type AB erythrocytes, as induced by isopropyl caffeate. The results are expressed as mean \pm SD analysis by ANOVA followed by Dunnett's test, ${ }^{*} p<0.05(n=3)$.

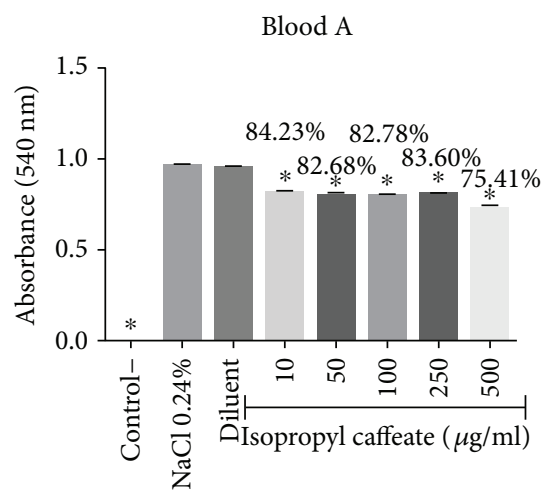

FIgURE 6: Antihemolytic evaluation in erythrocytes type A, induced by isopropyl caffeate, when in a hypotonic solution $(\mathrm{NaCl} 0.24 \%)$. The results are expressed as mean $\pm \mathrm{SD}$ analysis by ANOVA followed by post-Dunnett's test, ${ }^{*} p<0.05(n=3)$.

$300 \mathrm{mg} / \mathrm{kg}$. However, not having verified greater intensity in these effects, we cannot correlate dosage with acute toxic effect. Intense piloerection was observed, which is a sign of

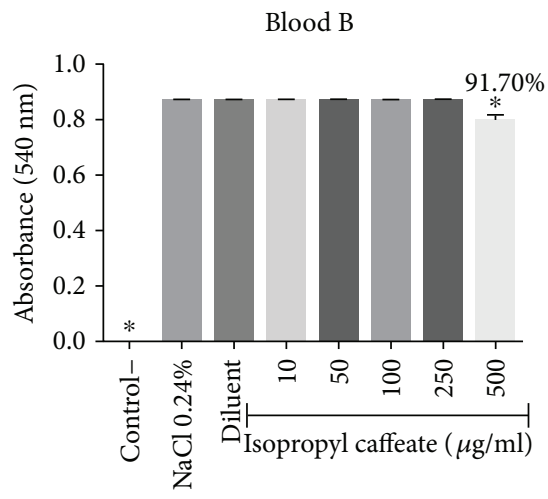

FIgURE 7: Antihemolytic evaluation in type B erythrocytes, as induced by isopropyl caffeate, when in a hypotonic solution $(\mathrm{NaCl}$ $0.24 \%)$. The results are expressed as mean \pm SD analysis by ANOVA followed by Dunnett's test, ${ }^{*} p<0.05(n=3)$.

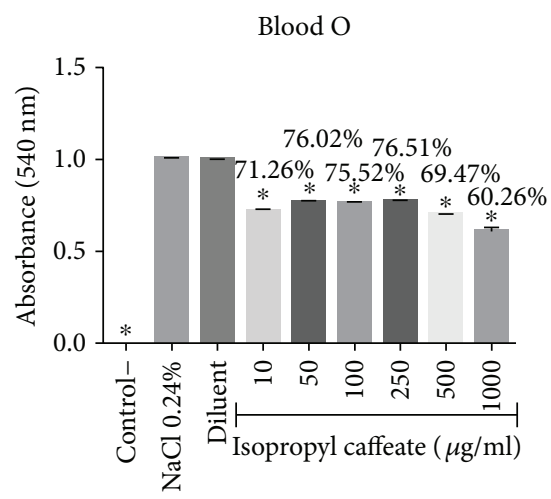

FIgUre 8: Antihemolytic evaluation in type O erythrocytes, as induced by isopropyl caffeate, when in a hypotonic solution $(\mathrm{NaCl} 0.24 \%)$. The results are expressed as mean $\pm \mathrm{SD}$ analysis by ANOVA followed by Dunnett's test, ${ }^{*} p<0.05(n=3)$.

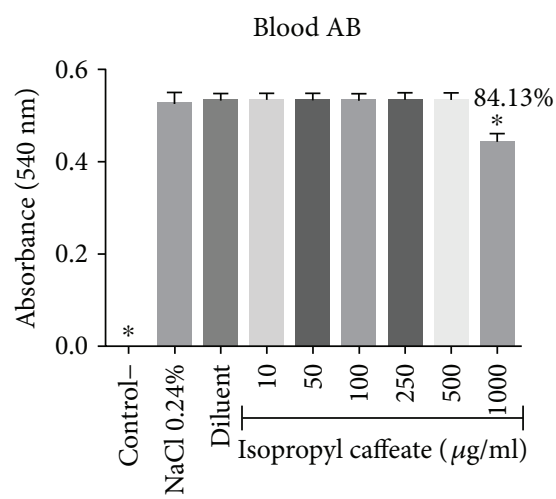

FIgURe 9: Antihemolytic evaluation in type $A B$ erythrocytes, induced by isopropyl caffeate, when in a hypotonic solution $(\mathrm{NaCl} 0.24 \%)$. The results are expressed as mean $\pm \mathrm{SD}$ analysis by ANOVA followed by Dunnett's test, ${ }^{*} p<0.05(n=3)$.

CNS stimulation. These behavioral changes disappeared after $24 \mathrm{~h}$ for both administrated doses. Also, isopropyl caffeate presented analgesia and induced catatonia at two 

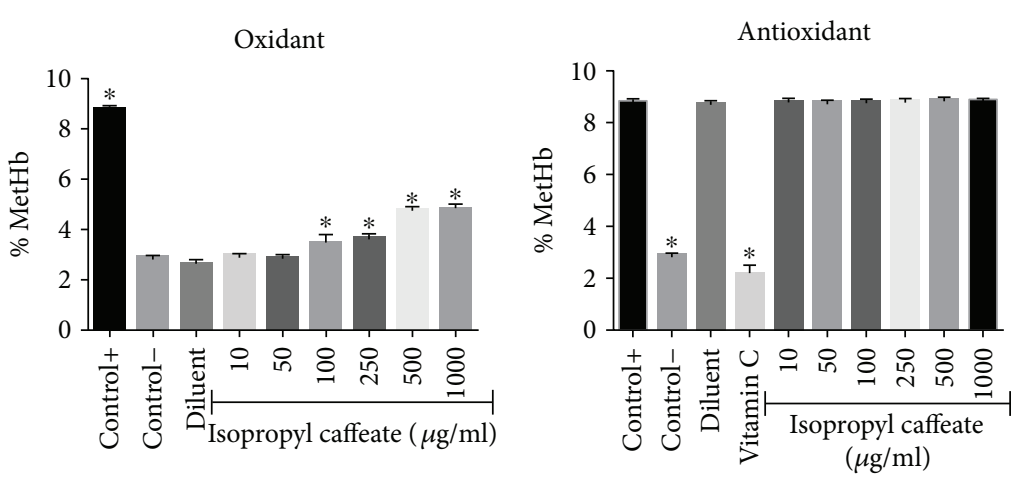

FIGURE 10: Oxidizing and antioxidant effects of isopropyl caffeate in human erythrocytes. The results are expressed as a percentage of average of formation of methemoglobin (MetHb) compared to the negative control group (oxidant test) and a positive control (antioxidant test). The results are expressed as mean \pm SD analysis by ANOVA followed by Dunnett's test, ${ }^{*} p<0.05(n=3)$.

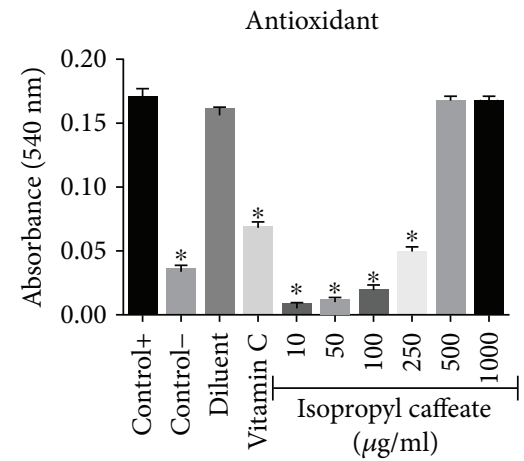

Figure 11: Antioxidant activity of isopropyl caffeate against hemolysis induced by hydrogen peroxide in blood type $\mathrm{O}$. Results are expressed as a percentage of average in comparison to the positive control group $\left(\mathrm{Hb}+\mathrm{H}_{2} \mathrm{O}_{2}\right)$. The results are expressed as mean $\pm \mathrm{SD}$ analysis by ANOVA followed by Dunnett's test, ${ }^{*} p<0.05(n=3)$.

of the treatment doses. However, this was not observed in all animals of the treated group; only a few were in fact brought to this effect which persisted for 3 hours. After eight days of administration, two animals died during the dose repetition process, at $2000 \mathrm{mg} / \mathrm{kg}$.

According to the "Globally Harmonized System of Classification" (GHS), isopropyl caffeate was considered in category $4\left(\mathrm{DL}_{50}>300-2000\right)$, according to guide number 423 of the OECD [28], and this category warning is necessary [35]; the $\mathrm{LD}_{50}$ was estimated at $2000 \mathrm{mg} / \mathrm{kg}$. This data corroborates the theoretical $\mathrm{LD}_{50}$ demonstrated by the admetSAR software that yielded $1.8847 \mathrm{~mol} / \mathrm{kg}$.

There was a statistically significant change (being the elevation of two compatible parameters) in the consumption of water and food and an increase in the weight gain of these same animals during the first week (animals treated with isopropyl caffeate at $300 \mathrm{mg} / \mathrm{kg}$ ). For the animals treated at a dose of $2000 \mathrm{mg} / \mathrm{kg}$, there was weight loss during the first week (Table 4).

3.9. In Vivo Acute Toxicity: Biochemical Parameters. We observed possible liver protective activity, since ALT and AST levels were lower in relation to the negative control group in the two treatment dosages. At the dose of $300 \mathrm{mg} /$ $\mathrm{kg}$, levels of urea decreased; this gives evidence of renal protection as well (Table 5).

3.10. In Vivo Acute Toxicity: Determination of MDA and NO. Again, we note potential protective action in the liver; in the animals treated at a dose of $300 \mathrm{mg} / \mathrm{kg}$, there was a statistically significant decrease in the production of MDA and consequent decreases in lipid peroxidation and oxidative stress. A decrease in the production of NO in the animals treated with a dose of $2000 \mathrm{mg} / \mathrm{kg}$ was verified. These results corroborate the PASS online software for the probability of being active with hepatoprotection (Figures 12 and 13).

3.11. In Vivo Acute Toxicity: Anatomopathological and Histopathological. In assessing organ weights, the spleen and lungs showed small significant variations as compared to the control group (Table 6), yet with no changes in structural integrity (Figure 14). The architecture of the renal parenchyma and circulatory system also presented no changes. The liver presented chronic inflammatory portal infiltration of mild to moderate intensity in two animals, however, not affecting the structure or normal architecture of this organ. There was no serious sign of substance toxicity (Figure 15). However, the stomach showed minimal edema and unspecific chronic inflammatory infiltration in the chorion, without inflammatory-destructive crypt activity or signs of gastric lesions induced by the drug (Figure 16).

\section{Discussion}

One way to predict the toxicity and pharmacokinetics of substances is through in silico tests, which assess the toxicity of theoretical compounds and aid in the choice of potentially promising molecules $[11,12,36]$. In silico tests revealed that isopropyl caffeate has no theoretical toxicity (Table 3) and has probable activity against several diseases which are directly linked to oxidation (Table 2).

From the in silico results, determination of cytotoxicity was performed using red blood cells since they contain high concentrations of polyunsaturated fatty acids, molecular oxygen, and ions linked in the ferrous state, making the cells 
TABLE 4: Effects of acute isopropyl caffeate treatment on the consumption of water and food and weight gain of treated female mice.

\begin{tabular}{lccccc}
\hline Groups & Dose $(\mathrm{mg} / \mathrm{kg})$ & Water $(\mathrm{ml})$ & Food $(\mathrm{g})$ & Weight gain (day 7) & Weight gain $($ day 14$)$ \\
\hline Control & - & $6.190 \pm 0.31$ & $4.697 \pm 0.14$ & $1.100 \pm 0.46$ & $1.100 \pm 0.46$ \\
Treated & 300 & $7.673 \pm 0.31^{*}$ & $5.536 \pm 0.19^{*}$ & $2.397 \pm 0.64^{*}$ & $0.772 \pm 0.10$ \\
Treated & 2000 & $6.884 \pm 0.35$ & $4.306 \pm 0.25$ & $-1.093 \pm 0.38^{*}$ & $0.375 \pm 0.28$ \\
\hline
\end{tabular}

The results are expressed as mean $\pm \mathrm{SD}$ analysis by ANOVA followed by Dunnett's test, ${ }^{*} p<0.05$ (control and treated at $300 \mathrm{mg} / \mathrm{kg}, n=6 / \mathrm{treated}$ at $2000 \mathrm{mg} / \mathrm{kg}, n=6$ in the first week and $n=4$ in the second week).

TABLE 5: Effects of acute isopropyl caffeate treatment on biochemical parameters of female mice.

\begin{tabular}{ccccccccc}
\hline Groups & $\begin{array}{c}\text { Dose } \\
(\mathrm{mg} / \mathrm{kg})\end{array}$ & $\begin{array}{c}\text { AST } \\
(\mathrm{U} / \mathrm{I})\end{array}$ & $\begin{array}{c}\text { ALT } \\
(\mathrm{U} / \mathrm{I})\end{array}$ & $\begin{array}{c}\text { Alkaline } \\
\text { phosphatase }(\mathrm{U} / \mathrm{I})\end{array}$ & $\begin{array}{c}\text { Serum creatinine } \\
(\mathrm{mg} / \mathrm{dl})\end{array}$ & $\begin{array}{c}\text { Urea } \\
(\mathrm{mg} / \mathrm{dl})\end{array}$ & $\begin{array}{c}\text { Glucose } \\
(\mathrm{mg} / \mathrm{dl})\end{array}$ & $\begin{array}{c}\text { Cholesterol } \\
(\mathrm{mg} / \mathrm{dl})\end{array}$ \\
\hline Control & - & $322.4 \pm 12.69$ & $144.5 \pm 12.55$ & $116.2 \pm 4.09$ & $0.31 \pm 0.02$ & $44.00 \pm 2.26$ & $188.3 \pm 5.58$ & $91.00 \pm 2.89$ \\
Treated & 300 & $177.2 \pm 17.58^{*}$ & $62.00 \pm 5.90^{*}$ & $125.5 \pm 9.19$ & $0.36 \pm 0.01^{*}$ & $34.40 \pm 2.38^{*}$ & $201.5 \pm 9.35$ & $88.83 \pm 3.29$ \\
Treated & 2000 & $166.5 \pm 20.90^{*}$ & $55.25 \pm 4.05^{*}$ & $103.3 \pm 11.79$ & $0.31 \pm 0.01$ & $42.67 \pm 2.33$ & $188.3 \pm 11.78$ & $97.33 \pm 5.49$ \\
\hline
\end{tabular}

The results are expressed as mean $\pm \mathrm{SD}$ analysis by ANOVA followed by post-Dunnett's test, ${ }^{*} p<0.05$ (control and dose of $300 \mathrm{mg} / \mathrm{kg} n=6 / \mathrm{dose}$ of $2000 \mathrm{mg} / \mathrm{kg} n=4)$.

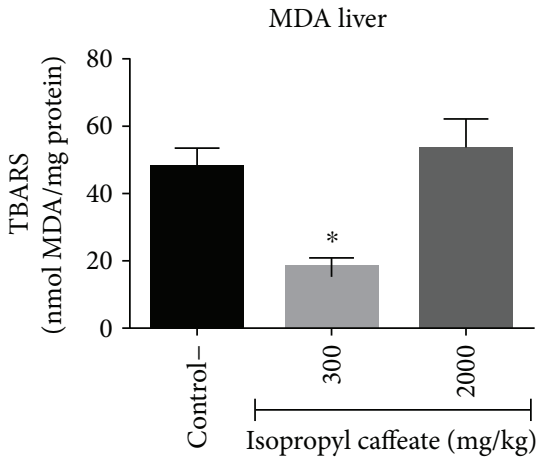

FIGURE 12: Dosage of malondialdehyde (MDA) of liver homogenate of $\mathrm{Balb} / \mathrm{c}$ females submitted to administration of isopropyl caffeate. The results are expressed as mean $\pm S D$ analysis by ANOVA followed by Dunnett's test, ${ }^{*} p<0.05$ (control and dose of $300 \mathrm{mg} / \mathrm{kg}, n=6 /$ dose of $2000 \mathrm{mg} / \mathrm{kg}, n=4)$.

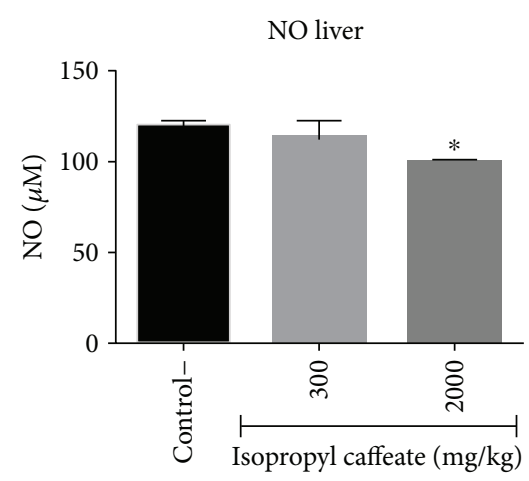

Figure 13: Determination of NO in liver homogenate of Balb/c females submitted to administration of isopropyl caffeate. The results are expressed as mean \pm SD analysis by ANOVA followed by Dunnett's test, ${ }^{*} p<0.05$ (control and dose of $300 \mathrm{mg} / \mathrm{kg}, n=6 /$ dose of $2000 \mathrm{mg} / \mathrm{kg}, n=4)$. highly vulnerable to reactions involving free radicals and susceptible to lipid peroxidation in cell membranes, which contributes to occurrences of hemolysis [37-39].

Another mechanism that may be related to hemolysis is erythrocyte apoptosis. Although erythrocytes do not have mitochondria that signal for this process, if there is exposure to ceramide or sphingosine, or an increasing concentration of cytosolic $\mathrm{Ca}^{2+} /\left(\left[\mathrm{Ca}^{2+}\right]_{\mathrm{i}}\right)$, oxidative stress and depletion of energy occur, the stimulation that leads to the erythrocyte apoptosis [40].

Cytotoxicity was also a measure of osmotic fragility, since cells become more osmotically fragile when there are changes in membrane lipids and proteins causing a reduction in the membrane integrity $[41,42]$. Changes in osmotic fragility may be related to the inhibition of enzyme activity and depletion of antioxidant defenses $[39,43]$.

The osmotic fragility results indicate that isopropyl caffeate causes significant changes in membrane proteins and in the structure of human erythrocyte lipids for the blood types $\mathrm{B}$ and $\mathrm{AB}$. However, the increase in osmotic fragility observed for blood type $A B$ may be due to interaction between isopropyl caffeate and aglutinogen $B$, since in blood type A, we observed a decrease in osmotic fragility, which was not verified in blood type $B$.

The phenylhydrazine is a powerful oxidizing agent that causes damage to hemoglobin through formation of hemichrome. In the heme group, a hydroxyl radical is added to hydroxilate a methene/phenyldiazene bridge (phenyldiazene is a derivative of phenylhydrazine) and binds to the heme group in 6th position, forming oxyhemoglobin [44]. As seen in Figure 10, isopropyl caffeate was not capable of inhibiting this mechanism.

Hydrogen peroxide is a key metabolite in oxidative stress [18, 45]. Phenolic compounds act as antioxidants due to aromatic ring hydroxyl substituent reactivity, and the mechanism of antioxidant activity is elimination of 
TABLE 6: Effects of acute isopropyl caffeate treatment on the content of the organs of female mice.

\begin{tabular}{lcccccccc}
\hline Groups & $\begin{array}{c}\text { Dose } \\
(\mathrm{mg} / \mathrm{kg})\end{array}$ & $\begin{array}{c}\text { Heart contents } \\
(\mathrm{mg} / \mathrm{g})\end{array}$ & $\begin{array}{c}\text { Lung index } \\
(\mathrm{mg} / \mathrm{g})\end{array}$ & $\begin{array}{c}\text { Stomach } \\
\text { contents }(\mathrm{mg} / \mathrm{g})\end{array}$ & $\begin{array}{c}\text { Liver contents } \\
(\mathrm{mg} / \mathrm{g})\end{array}$ & $\begin{array}{c}\text { Spleen index } \\
(\mathrm{Mg} / \mathrm{g})\end{array}$ & $\begin{array}{c}\text { Left kidney } \\
\text { index }(\mathrm{mg} / \mathrm{g})\end{array}$ & $\begin{array}{c}\text { Right kidney } \\
\text { index }(\mathrm{mg} / \mathrm{g})\end{array}$ \\
\hline Control & - & $5.06 \pm 0.12$ & $21.818 \pm 1.03$ & $10.89 \pm 0.47$ & $51.86 \pm 1.19$ & $7.04 \pm 0.42$ & $7.16 \pm 0.22$ & $7.07 \pm 0.29$ \\
Treated & 300 & $4.98 \pm 0.15$ & $5 \pm 3.18$ & $10.74 \pm 0.68$ & $55.99 \pm 1.64$ & $7.01 \pm 0.44$ & $7.66 \pm 0.18$ & $7.67 \pm 0.05$ \\
Treated & 2000 & $5.6 \pm 0.37$ & $14.9 \pm 2.42^{*}$ & $10.37 \pm 0.55$ & $53.69 \pm 2.87$ & $9.48 \pm 0.92^{*}$ & $7.24 \pm 0.16$ & $7.37 \pm 0.18$ \\
\hline
\end{tabular}

The results are expressed as mean \pm SD analysis by ANOVA followed by post-Dunnett's test, ${ }^{*} p<0.05(N=6)$.

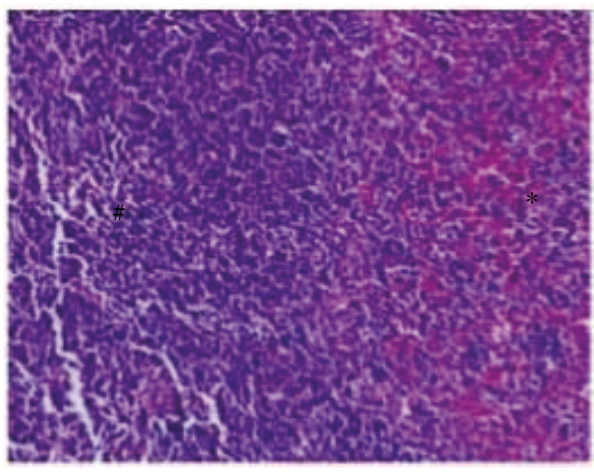

(a)

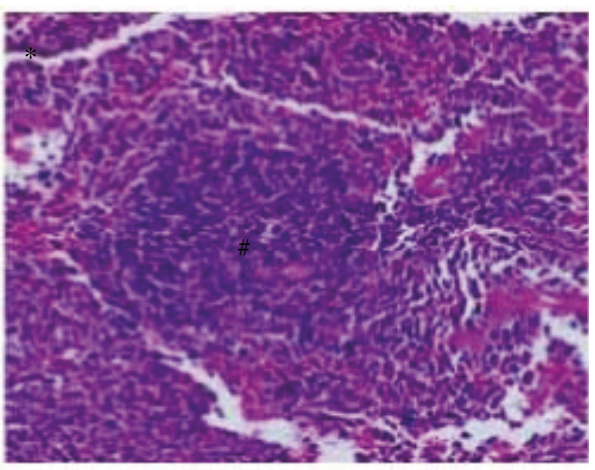

(b)

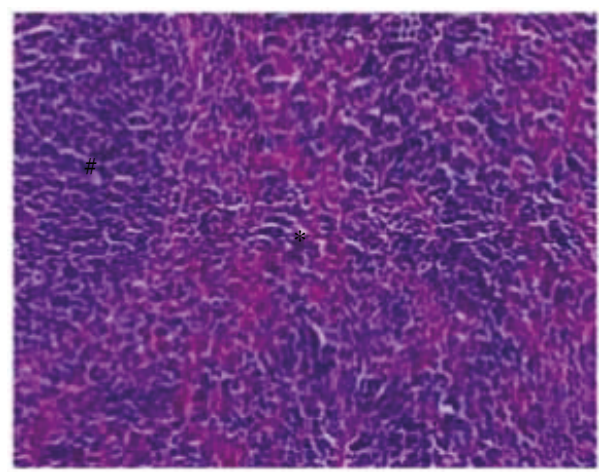

(c)

FIGURE 14: Spleen of treated Balb/c females V.O., stained with hematoxylin and eosin (increase 200x), there was no sign of toxicity in the spleen. Asterisks appoint red pulp and white flesh (\#) without special histological features. (a) Control group vehicle. (b) Group treated with a dose of $300 \mathrm{mg} / \mathrm{kg}$. (c) Group treated with a dose of $2000 \mathrm{mg} / \mathrm{kg}$.

the radical [2, 46]. Wang et al. [6] demonstrated the antioxidant activity of caffeic acid and its derivatives using the DPPH test; the compounds were considered potent antioxidants, presenting greater reducing of DPPH than vitamin C. Isopropyl caffeate presented better antioxidant activity than caffeic acid. The esterification of caffeic acid had a positive effect, increasing the antioxidant stability of the compound.

Potential toxicity of a substance refers to its ability to cause some imbalance in the body with which it comes into contact $[36,47]$. The analgesia presented by isopropyl caffeate suggests an antinociceptive profile due to a reduction in mechanical stimuli response [48, 49]. This result corroborates Buzzi et al. [7], who evaluated the antinociceptive properties of isopropyl caffeate and verified antinociceptive effect similar to certain therapeutic drugs such as acetylsalicylic acid, acetaminophen, and morphine. In substances that prevent both pain and inflammation, a certain correlation between antinociceptive and antioxidant properties has been demonstrated [50].

Drugs or drug therapies can readily cause catatonia $[51,52]$. The test result from the central nervous system for this substance is contrary to the theoretical admetSAR software results, which predicted that isopropyl caffeate should not pass the blood-brain barrier. The piloerection observed is a parameter that occurs in rodents as a result of fear, disease, or pharmacological stress [53-55]. In addition to behavioral variations, the toxicity of a compound can be demonstrated by means of changes in animal weight development, reduction in the consumption of water and food, and changes in the excretion of urine and feces [56, 57]. 


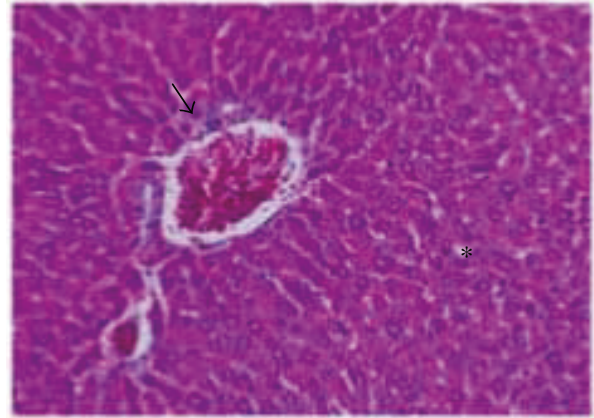

(a)

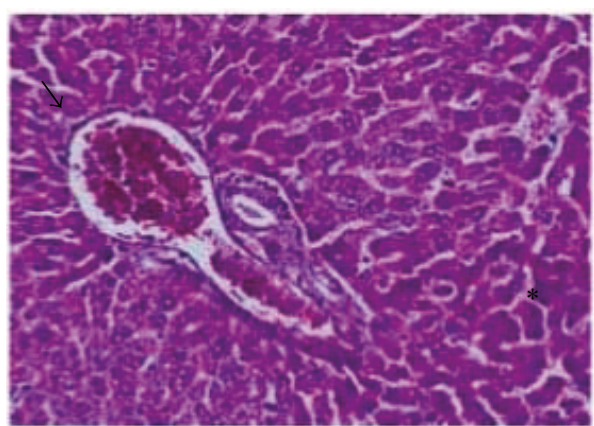

(c)

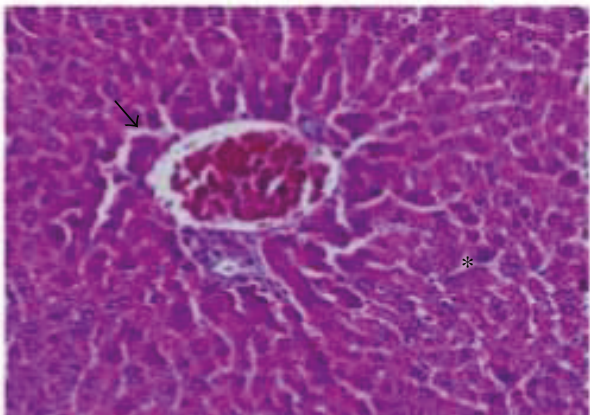

(b)

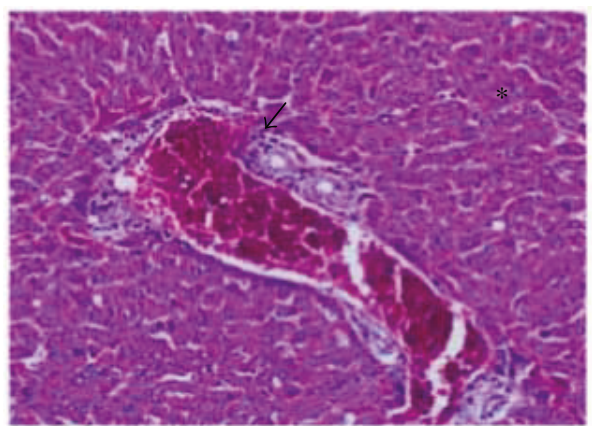

(d)

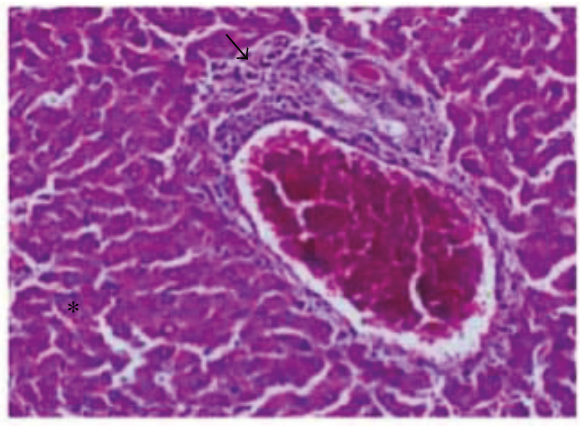

(e)

FigURE 15: Liver of treated Balb/c females V.O., stained with hematoxylin and eosin (increase 200x), there was no sign of toxicity in the liver. The arrows appoint portal spaces and the asterisks appoint normal hepatocytes. (a) Control group vehicle. (b) Group treated with a dose of $300 \mathrm{mg} / \mathrm{kg}$. (c) Group treated with a dose of $2000 \mathrm{mg} / \mathrm{kg}$. (d) Animal treated with a dose of $2000 \mathrm{mg} / \mathrm{kg}$ with little inflammatory infiltrate portal (portal spaces (arrow) with mild chronic inflammatory infiltration). (e) Animal treated with a dose of $2000 \mathrm{mg} / \mathrm{kg}$ (portal spaces (arrow) with moderate chronic inflammatory infiltration).

The weight gain of the animals may be affected by difficulty in digestion and absorption of food and nutrients, an indication of possible toxic effect [58-60]. However, the results are in agreement with OECD recommendations for body weight variation [28], which not exceed $20 \%$ variation in average weight (Table 4).

To evaluate hepatic and renal function after administration of isopropyl caffeate, investigation of biochemical parameters was performed. Such protective action may be linked to the antioxidant activity of isopropyl caffeate, since free radicals are responsible for diseases involving liver damage and kidney failure $[4,15]$ (Table 5).

Pang et al. [61] demonstrated caffeic acid's mechanism of protective action in vivo against hepatotoxicity induced by acetaminophen against liver cells. Caffeic acid is able to induce activation of $\mathrm{Nrf2}$, an important antioxidant transcription factor, reducing the expression of inhibitory protein Keap1 and blocking Nrf2 binding with Keap1, with consequent increased antioxidant enzyme (NQO1 and HO-1), expression which prevents oxidative lesions in the liver as induced by acetaminophen.

Another way to investigate liver function is through quantification of malondialdehyde (MDA) and nitric oxide (NO). Excessive production of MDA has been associated with various pathological states, since it is a secondary product formed during lipid peroxidation $[62,63]$. An elevated production of NO decreases regulation of cytochrome P450; it triggers suppression of hepatic proteins and the synthesis of DNA and thus induces apoptosis and necrosis [64, 65].

The liver, kidney, heart, spleen, and lungs are the organs most often affected by metabolic reactions caused by toxic 


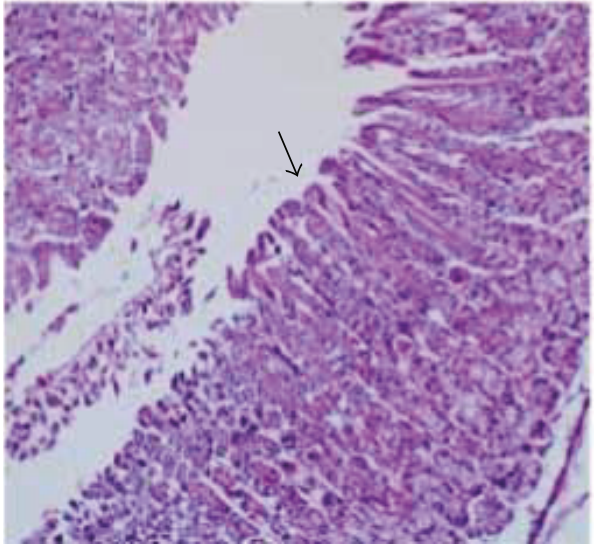

(a)

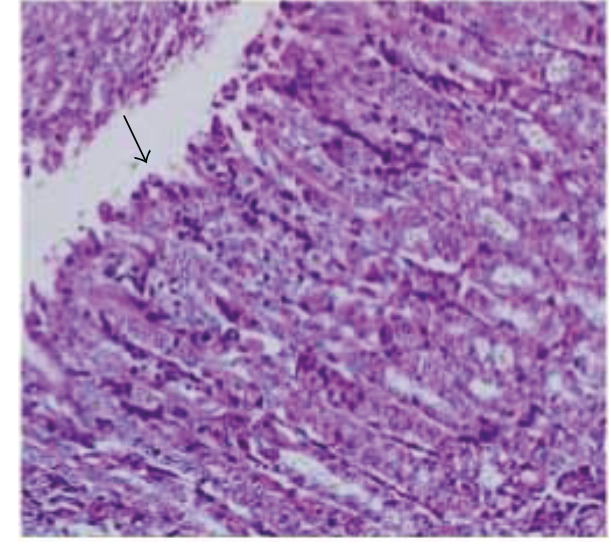

(b)

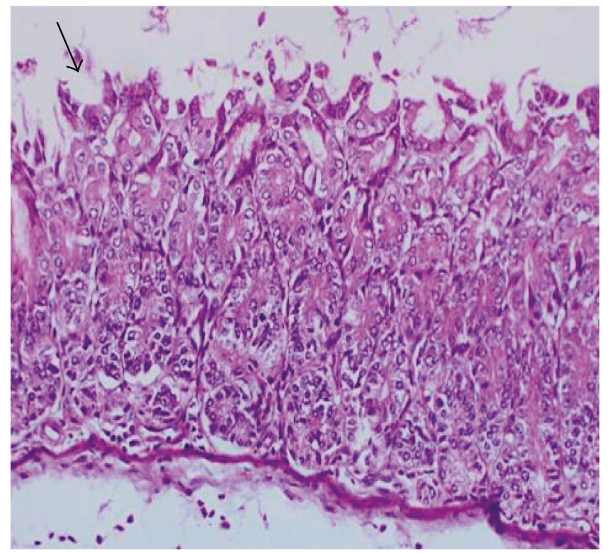

(c)

Figure 16: Stomach of treated Balb/c females V.O., stained with hematoxylin and eosin (increase 200x), there was no sign of toxicity in the stomach. The arrow appoints normal gastric mucosa. (a) Control group vehicle. (b) Group treated with a dose at $300 \mathrm{mg} / \mathrm{kg}$. (c) Group treated with a dose of $2000 \mathrm{mg} / \mathrm{kg}$.

agents [59]. Acute hepatotoxicity may be characterized as injury similar to hepatitis involving all areas of the gland, with hepatocellular ballooning, acidophilic hepatocyte degeneration, apoptotic bodies, small foci of necrosis, and discrete portal inflammation [66]. Thus, we note that isopropyl caffeate did not present elevated toxicity (corroborating the data calculated by the software) and also demonstrated possible hepatoprotection.

In conclusion, we note that isopropyl caffeate presents a range of pharmacological activities while demonstrating low cytotoxicity and in vivo toxicity, it protects cells in the presence of hypotonic solution, and does not compromise membrane structure, yet interferes in erythrocytic membrane functions. In this study, we reaffirm the antioxidant activity of isopropyl caffeate already presented in other studies as well as report other demonstrated effects such as elimination of free radicals. Isopropyl caffeate thus constitutes a promising option for the development of future drugs and may increase the available therapeutic arsenal.

\section{Conflicts of Interest}

The authors declare that they have no conflicts of interest.

\section{Acknowledgments}

This work was supported by the UFPB, CAPES, and CNPq.

\section{References}

[1] S. A. Heleno, A. Martins, M. J. R. P. Queiroz, and I. C. F. R. Ferreira, "Bioactivity of phenolic acids: metabolites versus parent compounds: a review," Food Chemistry, vol. 173, pp. 501-513, 2015.

[2] S. S. Damasceno, B. B. Dantas, J. Ribeiro-Filho, D. Antônio M Araújo, and J. Galberto M da Costa, "Chemical properties of caffeic and ferulic acids in biological system: implications in cancer therapy. A review," Current Pharmaceutical Design, vol. 23, no. 20, pp. 3015-3023, 2017.

[3] H. Zhang and R. Tsao, "Dietary polyphenols, oxidative stress and antioxidant and anti-inflammatory effects," Current Opinion in Food Science, vol. 8, pp. 33-42, 2016.

[4] H. Sies, C. Berndt, and D. P. Jones, "Oxidative stress," Annual Review of Biochemistry, vol. 86, no. 1, pp. 715-748, 2017.

[5] W. Li, N. Li, Y. Tang et al., "Biological activity evaluation and structure-activity relationships analysis of ferulic acid and caffeic acid derivatives for anticancer," Bioorganic \& Medicinal Chemistry Letters, vol. 22, no. 19, pp. 60856088, 2012. 
[6] J. Wang, S. S. Gu, N. Pang et al., "Alkyl caffeates improve the antioxidant activity, antitumor property and oxidation stability of edible oil," PLoS One, vol. 9, no. 4, article e95909, 2014.

[7] F. de Campos Buzzi, C. L. Franzoi, G. Antonini et al., "Antinociceptive properties of caffeic acid derivatives in mice," European Journal of Medicinal Chemistry, vol. 44, no. 11, pp. 4596-4602, 2009.

[8] K. S. Bhullar, G. Lassalle-Claux, M. Touaibia, and H. P. V. Rupasinghe, "Antihypertensive effect of caffeic acid and its analogs through dual renin-angiotensin-aldosterone system inhibition," European Journal of Pharmacology, vol. 730, pp. 125-132, 2014.

[9] D. de Vita, L. Friggeri, F. D. D’Auria et al., "Activity of caffeic acid derivatives against Candida albicans biofilm," Bioorganic \& Medicinal Chemistry Letters, vol. 24, no. 6, pp. 1502-1505, 2014.

[10] P. A. Nogara, R. . A. Saraiva, D. Caeran Bueno et al., "Virtual screening of acetylcholinesterase inhibitors using the Lipinski's rule of five and zinc databank," BioMed Research International, vol. 2015, Article ID 870389, 8 pages, 2015.

[11] A. I. Dirar, A. Y. Waddad, M. A. Mohamed et al., "In silico pharmacokinetics and molecular docking of three leads isolated from Tarconanthus camphoratus L," International Journal of Pharmacy and Pharmaceutical Sciences, vol. 8, no. 5, pp. 71-77, 2016.

[12] S. Ud-Din and A. Bayat, "Non-animal models of wound healing in cutaneous repair: in silico, in vitro, ex vivo and in vivo models of wounds and scars in human skin," Wound Repair and Regeneration, vol. 25, no. 2, pp. 164-176, 2017.

[13] P. A. S. White, R. C. M. Oliveira, A. P. Oliveira et al., "Antioxidant activity and mechanisms of action of natural compounds isolated from lichens: a systematic review," Molecules, vol. 19, no. 9, pp. 14496-14527, 2014.

[14] H. Yasmeen and S. Hassnain, "Comparative analysis of different bioactivities of Curcuma longa, Nigella sativa seeds, and Camellia sinensis extracted by four different methods: a green way to reduce oxidative stress," Food Science and Biotechnology, vol. 25, no. 3, pp. 811-819, 2016.

[15] P. Poprac, K. Jomova, M. Simunkova, V. Kollar, C. J. Rhodes, and M. Valko, "Review targeting free radicals in oxidative stress-related human diseases," Trends in Pharmacological Sciences, vol. 38, no. 7, pp. 592-607, 2017.

[16] A. Bag, S. Kumar Bhattacharyya, N. Kumar Pal, and R. Ranjan Chattopadhyay, "Anti-inflammatory, anti-lipid peroxidative, antioxidant and membrane stabilizing activities of hydroalcoholic extract of Terminalia chebula fruits," Pharmaceutical Biology, vol. 51, no. 12, pp. 1515-1520, 2013.

[17] Z.-J. Wang, J.-H. Xie, S.-P. Nie, and M.-Y. Xie, "Review on cell models to evaluate the potential antioxidant activity of polysaccharides," Food \& Function, vol. 8, no. 3, pp. 915926, 2017.

[18] H. Zhang, M. Yin, L. Huang et al., "Evaluation of the cellular and animal models for the study of antioxidant activity: a review," Journal of Food Science, vol. 82, no. 2, pp. 278-288, 2017.

[19] M. O. De Farias, T. C. Lima, A. L. A. L. Pérez et al., “Antifungal activity of ester derivatives from caffeic acid against Candida species," International Journal of Pharmacy \& Pharmaceutical Research, vol. 7, no. 1, pp. 151-159, 2016.
[20] K. Uwai, Y. Osanai, T. Imaizumi, S. I. Kanno, M. Takeshita, and M. Ishikawa, "Inhibitory effect of the alkyl side chain of caffeic acid analogues on lipopolysaccharide-induced nitric oxide production in RAW264.7 macrophages," Bioorganic \& Medicinal Chemistry, vol. 16, no. 16, pp. 7795-7803, 2008.

[21] P. Ertl, B. Rohde, and P. Selzer, "Fast calculation of molecular polar surface area as a sum of fragment-based contributions and its application to the prediction of drug transport properties," Journal of Medicinal Chemistry, vol. 43, no. 20, pp. 37143717, 2000.

[22] N. Srinivas, K. S. Sandeep, Y. Anusha, and B. N. Devendra, "In vitro cytotoxic evaluation and detoxification of monocrotaline (Mct) alkaloid: an in silico approach," International Invention Journal of Biochemistry and Bioinformacts, vol. 2, no. 2, pp. 20-29, 2014.

[23] O. M. Bautista-Aguilera, G. Esteban, I. Bolea et al., "Design, synthesis, pharmacological evaluation, QSAR analysis, molecular modeling and ADMET of novel donepezil-indolyl hybrids as multipotent cholinesterase/monoamine oxidase inhibitors for the potential treatment of Alzheimer's disease," European Journal of Medicinal Chemistry, vol. 75, pp. 82-95, 2014.

[24] M. Rangel, E. L. A. Malpezzi, S. M. M. Susini, and J. C. De Freitas, "Hemolytic activity in extracts of the diatom Nitzschia," Toxicon, vol. 35, no. 2, pp. 305-309, 1997.

[25] J. Dacie and S. M. Lewis, Practical Haematology, Churchill Livingstone, London, 2001.

[26] K. A. Arbos, L. M. Claro, L. Borges, C. A. M. Santos, and A. M. Weffort-Santos, "Human erythrocytes as a system for evaluating the antioxidant capacity of vegetable extracts," Nutrition Research, vol. 28, no. 7, pp. 457-463, 2008.

[27] M. Khalili, M. A. Ebrahimzadeh, and Y. Safdari, "Antihaemolytic activity of thirty herbal extracts in mouse red blood cells," Archives of Industrial Hygiene and Toxicology, vol. 65, no. 4, pp. 399-406, 2014.

[28] OECD, Guideline for Testing of Chemicals/Section 4: Helth Effects Test no. 423: Acute Oral Toxicity-Acute Toxic Class Method, Organization for Economic Cooperation and Development, Paris, France, 2001.

[29] R. N. Almeida, A. C. G. M. Falcão, R. S. T. Diniz et al., "Metodologia para avaliação de plantas com atividade no sistema nervoso central e alguns dados experimentais," Revista Brasileira de Farmácia, vol. 80, pp. 72-76, 1999.

[30] H. Ohkawa, N. Ohishi, and K. Yagi, "Assay for lipid peroxides in animal tissues by thiobarbituric acid reaction," Analytical Biochemistry, vol. 95, no. 2, pp. 351-358, 1979.

[31] D. Giustarini, R. Rossi, A. Milzani, and I. Dalle-Donne, "Nitrite and nitrate measurement by Griess reagent in human plasma: evaluation of interferences and standardization," Methods in Enzymology, vol. 440, pp. 361-380, 2008.

[32] L. G. Luna, Manual of Histologic Staining Methods of the Armed Forces Institute of Pathology, McGraw-Hill, New York, NY, USA, 3rd edition, 1968.

[33] A. VERMA, "Lead finding from Phyllanthus debelis with hepatoprotective potentials," Asian Pacific Journal of Tropical Biomedicine, vol. 2, no. 3, pp. S1735-S1737, 2012.

[34] S. K. Paramashivam, K. Elayaperumal, B. B. Natarajan, M. D. Ramamoorthy, S. Balasubramanian, and K. N. Dhiraviam, "In silico pharmacokinetic and molecular docking studies of small molecules derived from Indigofera aspalathoides Vahl targeting receptor tyrosine kinases," Bioinformation, vol. 11, no. 2, pp. 73-84, 2015. 
[35] UN, Globally Harmonized System of Classification and Labelling of Chemicals (GHS), United Nations, New York and Geneva, 4th edition, 2011.

[36] A. B. Raies and V. B. Bajic, "In silico toxicology: comprehensive benchmarking of multi-label classification methods applied to chemical toxicity data," WIREs Computational Molecular Science, article e1352, 2017.

[37] A. Duarte, E. Waczuk, K. Roversi et al., "Polyphenolic composition and evaluation of antioxidant activity, osmotic fragility and cytotoxic effects of Raphiodon echinus (Nees \& Mart.) Schauer," Molecules, vol. 21, no. 12, p. 2, 2016.

[38] E. Olchowik-Grabarek, K. Makarova, S. Mavlyanov, N. Abdullajanova, and M. Zamaraeva, "Comparative analysis of BPA and HQ toxic impacts on human erythrocytes, protective effect mechanism of tannins (Rhus typhina)," Environmental Science and Pollution Research, vol. 25, no. 2, pp. 1200-1209, 2018.

[39] K. G. Ibrahim, B. W. Lembede, E. Chivandi, and K. Erlwanger, "Erythrocyte osmotic fragility and general health status of adolescent Sprague Dawley rats supplemented with Hibiscus sabdariffa aqueous calyx extracts as neonates followed by a high-fructose diet post-weaning," Journal of Animal Physiology and Animal Nutrition, vol. 102, no. 1, pp. 114-121, 2018.

[40] E. Signoretto, J. Zierle, A. A. M. Bhuyan, M. Castagna, and F. Lang, "Ceranib-2-induced suicidal erythrocyte death," Cell Biochemistry and Function, vol. 34, no. 5, pp. 359366, 2016.

[41] F. A. Ansari, S. N. Ali, and R. Mahmood, "Sodium nitriteinduced oxidative stress causes membrane damage, protein oxidation, lipid peroxidation and alters major metabolic pathways in human erythrocytes," Toxicology In Vitro, vol. 29, no. 7, pp. 1878-1886, 2015.

[42] A. D. Nigra, N. E. Monesterolo, J. F. Rivelli et al., "Alterations of hemorheological parameters and tubulin content in erythrocytes from diabetic subjects," The International Journal of Biochemistry \& Cell Biology, vol. 74, pp. 109-120, 2016.

[43] D. B. Santos, V. P. P. Schiar, M. W. Paixão et al., "Hemolytic and genotoxic effects of organochalcogens in human blood cells in vitro," Toxicology In Vitro, vol. 23, no. 6, pp. 11951204, 2009.

[44] E. M. Welbourn, M. T. Wilson, A. Yusof, M. V. Metodiev, and C. E. Cooper, "The mechanism of formation, structure and physiological relevance of hemoglobin covalent attachment to the erythrocyte membrane," Free Radical Biology \& Medicine, vol. 103, pp. 95-106, 2017.

[45] H. Sies, "Hydrogen peroxide as a central redox signaling molecule in physiological oxidative stress: oxidative eustress," Redox Biology, vol. 11, pp. 613-619, 2017.

[46] D. Stojković, J. Petrović, M. Soković, J. Glamočlija, J. KukićMarković, and S. Petrović, "In situ antioxidant and antimicrobial activities of naturally occurring caffeic acid, $p$-coumaric acid and rutin, using food systems," Journal of the Science of Food and Agriculture, vol. 93, no. 13, pp. 3205-3208, 2013.

[47] A. G. Santos and L. C. Pereira, "Using alternative methods to animal testing in research," Journal of the Brazilian Society of Science in Laboratory Animals, vol. 4, no. 1, pp. 22-31, 2016.

[48] R. N. Almeida and T. M. L. Oliveira, "Pharmacological screening behavioral," in No Psychopharmacology: practical foundations, ch. 11, R. Almeida, Ed., pp. 131-137, Guanabara Koogan, Rio de Janeiro, 1st edition, 2006.
[49] V. La Rocca, D. V. da Fonsêca, K. S. Silva-Alves et al., "Geraniol induces antinociceptive effect in mice evaluated in behavioural and electrophysiological models," Basic \& Clinical Pharmacology \& Toxicology, vol. 120, no. 1, pp. 22-29, 2017.

[50] C. C. de Menezes Patrício Santos, M. S. Salvadori, V. G. Mota et al., "Antinociceptive and antioxidant activities of phytol in vivo and in vitro models," Neuroscience Journal, vol. 2013, Article ID 949452, 9 pages, 2013.

[51] J. Antunes, N. Urbano, J. Estrada et al., "Catatonia em um adolescente após uso de mefedrona comodroga recreativa," Scientia Medica, vol. 23, no. 3, pp. 175-179, 2013.

[52] M. Khan, L. Pace, A. Truong, M. Gordon, and N. Moukaddam, "Catatonia secondary to synthetic cannabinoid use in two patients with no previous psychosis," The American Journal on Addictions, vol. 25, no. 1, pp. 25-27, 2016.

[53] D. Estork, D. Gusmão, M. Paciencia et al., "First chemical evaluation and toxicity of Casinga-cheirosa to Balb-C male mice," Molecules, vol. 19, no. 4, pp. 3973-3987, 2014.

[54] P. J. Lang, "Emotion's response patterns: the brain and the autonomic nervous system," Emotion Review, vol. 6, no. 2, pp. 93-99, 2014.

[55] A. Rajagopalan, K. V. Jinu, K. S. Sailesh, S. Mishra, U. K. Reddy, and J. K. Mukkadan, "Understanding the links between vestibular and limbic systems regulating emotions," Journal of Natural Science, Biology and Medicine, vol. 8, no. 1, pp. 11-15, 2017.

[56] H. Kato, M. Tsuji, K. Miyagawa, K. Takeda, and H. Takeda, "Repeated exposure to stress stimuli during ethanol consumption prolongs withdrawal-induced emotional abnormality in mice," European Journal of Pharmacology, vol. 721, no. 1-3, pp. 29-34, 2013.

[57] L. Wang, M. Goebel-Stengel, P. Q. Yuan, A. Stengel, and Y. Taché, "Corticotropin-releasing factor overexpression in mice abrogates sex differences in body weight, visceral fat, and food intake response to a fast and alters levels of regulatory hormones," Biology of Sex Differences, vol. 8, p. 2, 2017.

[58] L. C. L. R. Santana, M. R. M. Brito, G. F. Sousa, and R. M. Freitas, "Estudo das propriedades físico-químicas e avaliação da toxicidade aguda do extrato etanólico das folhas de Mikania glomerata Sprengel," Brazilian Journal of Medicinal Plants, vol. 16, no. 3, pp. 670-678, 2014.

[59] S. Roy, S. Majumdar, A. K. Singh et al., "Synthesis, characterization, antioxidant status, and toxicity study of vanadiumrutin complex in Balb/c mice," Biological Trace Element Research, vol. 166, no. 2, pp. 183-200, 2015.

[60] M. Sayyad, N. Tiang, Y. Kumari et al., "Acute toxicity profiling of the ethyl acetate fraction of Swietenia macrophylla seeds and in-vitro neuroprotection studies," Saudi Pharmaceutical Journal, vol. 25, no. 2, pp. 196-205, 2017.

[61] C. Pang, Z. Zheng, L. Shi et al., "Caffeic acid prevents acetaminophen-induced liver injury by activating the Principe1-Nrf2 antioxidative defense system," Free Radical Biology \& Medicine, vol. 91, pp. 236-246, 2016.

[62] A. Ayala, M. F. Muñoz, and S. Argüelles, "Lipid peroxidation: production, metabolism, and signaling mechanisms of malondialdehyde and 4-hydroxy-2-nonenal," Oxidative Medicine and Cellular Longevity, vol. 2014, Article ID 360438, 31 pages, 2014.

[63] M. A. Ghani, C. Barril, D. R. Bedgood Jr., and P. D. Prenzler, "Substrate and TBARS variability in a multi-phase oxidation 
system," European Journal of Lipid Science and Technology, vol. 119, no. 4, article 1500500, 2016.

[64] A. R. Vince, M. A. Hayes, B. J. Jefferson, and M. J. Stalker, "Hepatic injury a with apoptosis, regeneration, and nitric oxide synthase expression in chronic liver disease," Veterinary Pathology, vol. 51, no. 5, pp. 932-945, 2014.

[65] N. N. Kabil, H. A. Seddiek, N. A. Yassin, and M. M. Gamal-Eldin, "Effect of ghrelin on chronic liver injury and fibrogenesis in male rats: possible role of nitric oxide," Peptides, vol. 52, pp. 90-97, 2014.

[66] Z. D. Goodman, "Phenotypes and pathology of druginduced liver disease," Clinics in Liver Disease, vol. 21, no. 1, pp. 89-101, 2017. 


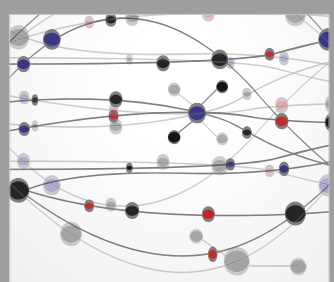

The Scientific World Journal
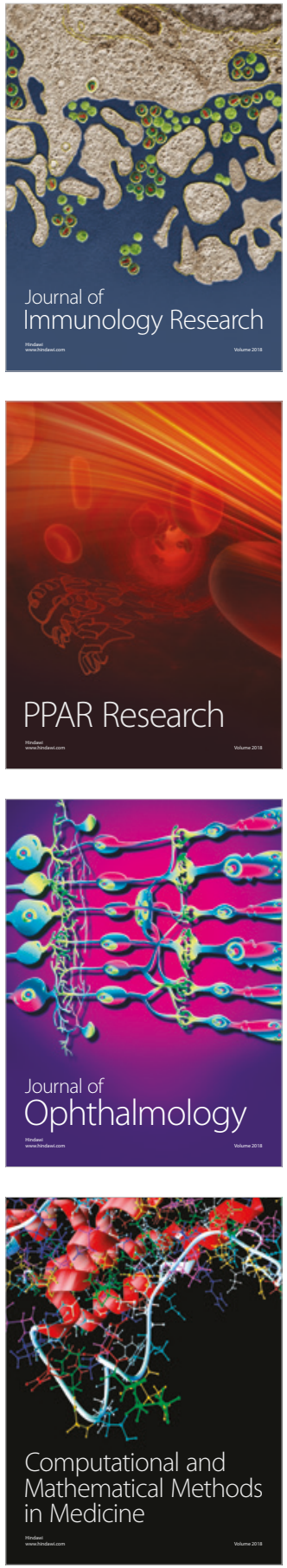

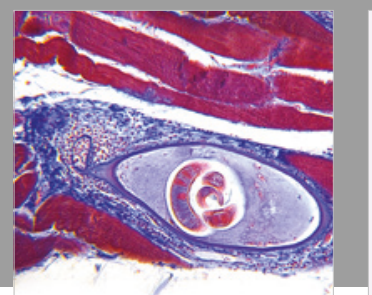

Gastroenterology Research and Practice

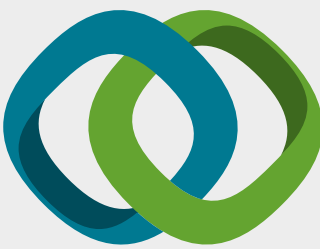

\section{Hindawi}

Submit your manuscripts at

www.hindawi.com
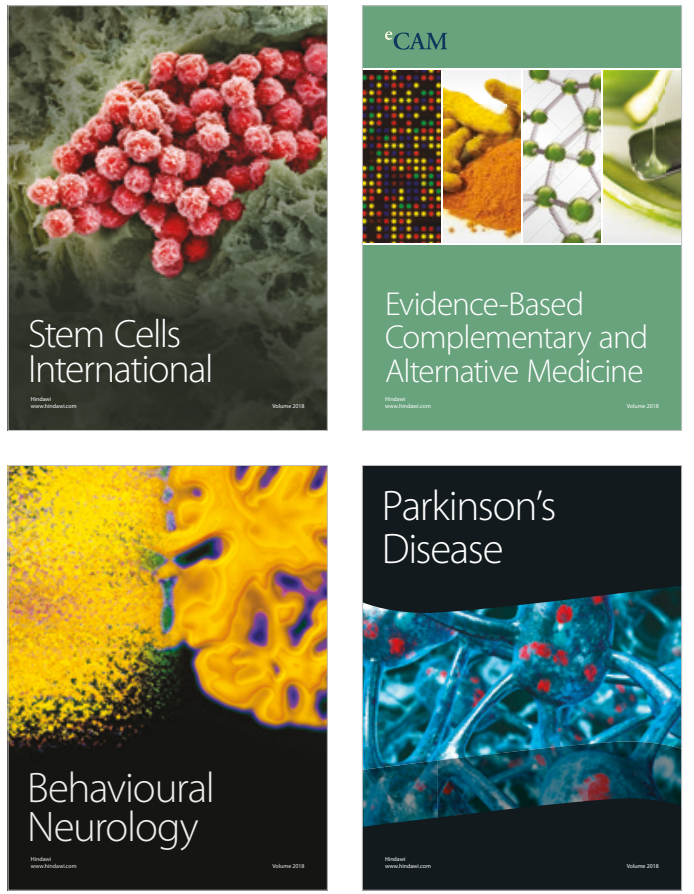

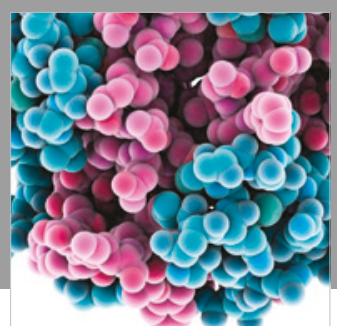

ournal of

Diabetes Research

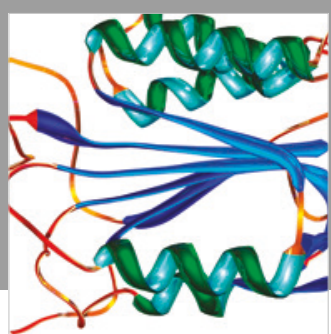

Disease Markers
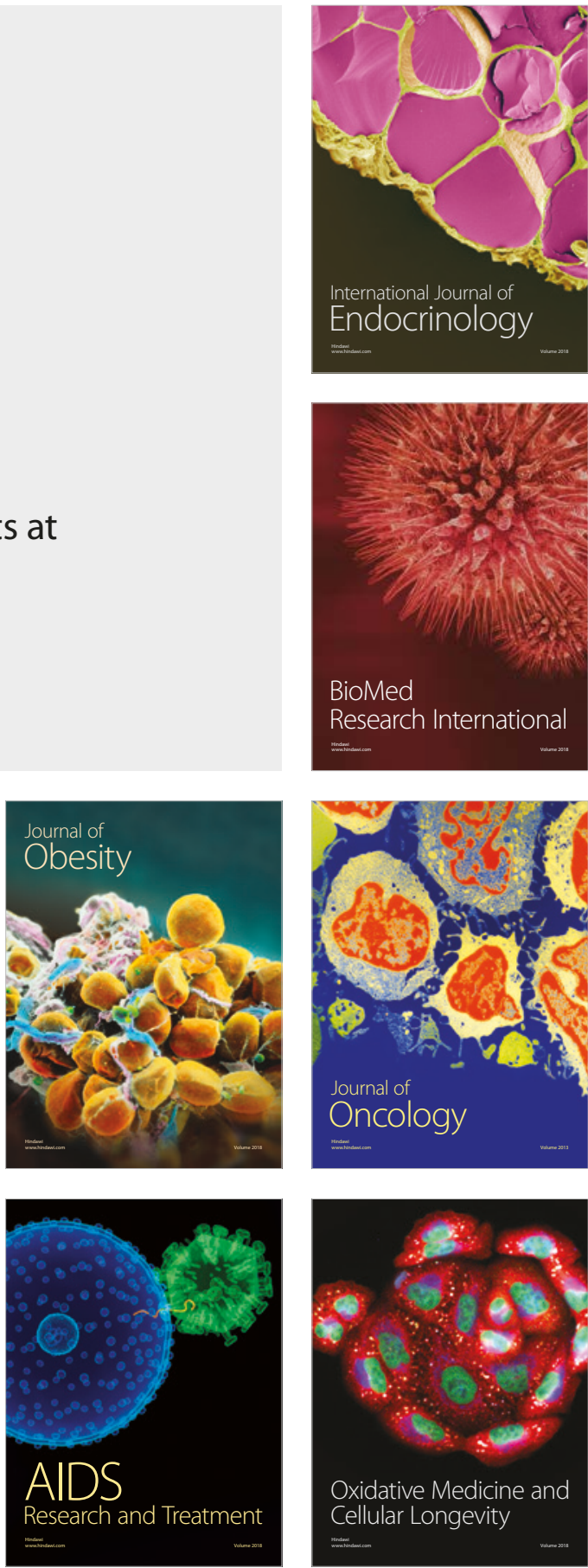